\title{
Egg-laying and brochosome production observed in glassy-winged sharpshooter
}

\author{
Raymond L. Hix
}

\begin{abstract}
Glassy-winged sharpshooter (GWSS) females form white spots on the forewings from secretions of ultramicroscopic bodies known as brochosomes. This occurs after mating of the GWSS and just prior to egg laying. The first published reports of wing spots were made by Riley and Howard in 1893. The behaviors associated with brochosome formation could have important implications for integrated pest management (IPM) programs to control GWSS, an important vector of the bacterium that causes Pierce's disease in grapevines and other crops.
\end{abstract}

Since 1997, wineries near Temecula $\mathcal{S}$ have lost $20 \%$ to $30 \%$ of their vines to Pierce's disease, which is caused by the bacterium Xylella fastidiosa Wells and can be transmitted by the glassywinged sharpshooter (GWSS), Homalodisca coagulata (Say) (Homoptera: Cicadellidae). GWSS was inadvertently introduced into California from the southeastern United States (Sorensen and Gill 1996). Diseases caused by the bacterium vectored by GWSS in California include Pierce's disease, almond leaf scorch, alfalfa dwarf and oleander leaf scorch. GWSS feeds on plant stems yearround, even on dormant plants. Large populations have been found near grapes in Bakersfield (Kern County) and the Coachella Valley (Riverside County), raising concerns for crops in these regions.

Few studies have investigated the mating and oviposition behavior of GWSS. This information could be important for developing or improving effective integrated pest management (IPM) programs, especially aspects related to insect monitoring. We briefly discuss what is known about GWSS egg-laying behavior, and present studies from my laboratory. The implications of wing-spot formation and brochosome secretions are discussed in the context of IPM programs. All GWSS brochosome secretions are either grayish translucent or opaque white in comparison to the clear excrement often referred to as "hopper rain."

\section{Historical perspective}

Before the turn of the 20th century, Riley and Howard (1893) dispatched Nathan Banks and F.W. Mally to Shreveport, La., to investigate problems in cotton with the GWSS, referred to locally as a "sharpshooter" attack. They determined that GWSS populations were breeding in poplars and moving into adjacent cotton. (This is similar to the current situation in Southern California, where GWSS populations often build up in citrus and move into grape.) Riley and Howard reported that female GWSS had powdery white spots on the forewings. Their report indicated that the spots easily rubbed off and were not apparent after the insect was a few days old. They thought the material was waxy in nature.

Swain (1936) reported similar spots on the sharpshooter Oncometopia undata Fabricius (Homoptera: Cicadellidae) and described its oviposition behavior. The behavior of $O$. undata is similar to that of GWSS in that the females scrape off the white spots with their hind tibia onto the eggs and leaf surface between ovipositing eggs. Swain recognized that these spots weren't merely ornaments, but he wasn't sure as to their origin. He supposed them to be transferred to the forewings by the hind tibia from the anus. The powdering of the egg mass was believed to camouflage the eggs from predators and parasites.

The makeup, origin and function of white spots in certain leafhoppers

\section{Insect glossary}

Brochosomes - ultramicroscopic reticulated bodies produced in the Malpighian tubules of leafhoppers

Cicadellidae - the family of insects including the leafhoppers and sharpshooters

Eclosion - escape of the adult GWSS from the cuticle of the 5 th instar nymph

Instar - stage between molts in the nymph or larvae

Integrated pest management (IPM) optimum combination of control methods including biological, cultural, mechanical, physical and/or chemical controls to reduce pest populations to an economical acceptable level with as few harmful effects as possible on the environment and nontarget organisms

Malpighian tubule - thin tubes arising near the junction of the hind and midgut involved in amino acid synthesis, nitrogenous excretion, water regulation and secretory activities

Nymph - an immature stage of hemimetabolous insects, e.g., leafhoppers

Oviposition - egg laying

Ovipositor - the organ by which eggs are deposited

Stylets - needlelike mouthparts of piercing-sucking insects

Tibia - long leg segment located between femur and tarsus (pl. tarsi) 


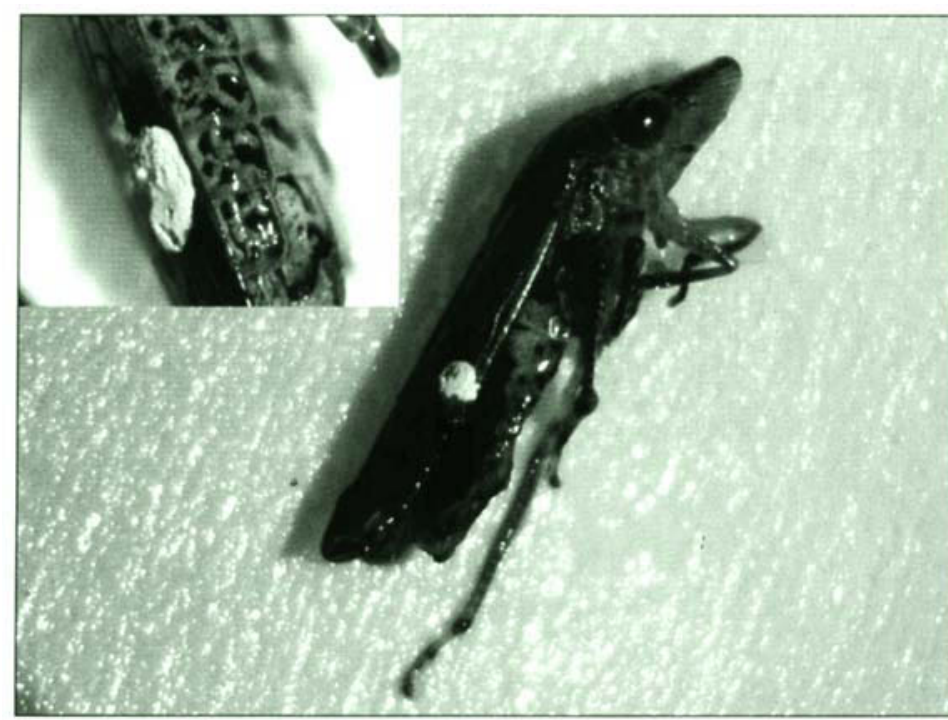

Female GWSS on experimental sticky trap, depicting forewing spots of brochosomes; inset, close-up of a brochosome.

(Homoptera: Cicadellidae) are somewhat enigmatic. The association of ultramicroscopic bodies with leafhoppers was reported and subsequently named "brochosomes" (Tulloch and Shapiro 1953). Brochosomes were described as hollow spheroids varying in size from 0.3 to 6.0 micrometers in diameter. While the brochosomes were associated with certain insects, Tulloch and collaborators were uncertain if they were of insect origin.

Day and Briggs (1958) determined that brochosomes were produced by the Malpighian tubules. Smith and Littau (1960) confirmed this and reported that the brochosomes contained protein and lipid components.

Neilson, May and Tingey (1975) described the preoviposition and oviposition behavior of a related sharpshooter, Oncometopia alpha. Its behavior was very similar to GWSS in that it applied a liquid material from its anus to the forewings with the hind tibia. The material dried to a white chalky condition. This sharpshooter also covered its egg masses by scraping the material off of the forewings with the hind tibia. However, the researchers didn't recognize the material as brochosomes at the time.

Mayse (1981) reported that only female Oncometopia orbona (F.) secreted and placed the chalky material on the wings. He also stated that although fe- males scraped the material off the wings and onto their egg masses, they sometimes scraped it off without associated oviposition behavior. Mayse reported that the chalky material contained allantoin and urea, but never specifically referred to it as brochosomes.

It is now known that several species of leafhoppers secrete brochosomes (Rakitov 2000). Brochosomes are generally either spherical or rod shaped. Males, nymphs and females may produce spherical brochosomes, but only females are known to produce rodshaped brochosomes. Typically, the rodshaped brochosomes are applied to the forewings by most leafhopper species and sometimes to the egg masses. Both sexes and nymphs of some species apply the spherical brochosomes to various parts of the body during anointing behavior. The literature is unclear about whether females of the species studied must mate before secreting rod-shaped brochosomes, or if all species spread brochosomes onto their eggs or egg masses.

\section{Oviposition behavior}

To better understand the secretion of brochosomes, female GWSS and mating pairs were studied in the laboratory. Knowledge of GWSS biology and the role of brochosomes may lead to new ideas for IPM and GWSS control.

Oviposition behaviors were recorded by a CCD video camera equipped with a macro zoom lens, or data was recorded verbally onto a cassette recorder and transcribed to notes. These events are based on video analysis and observations of 35 complete mating cycles with virgin insects reared and maintained in a colony. The mean of the observation times for the 35 sessions was 12.2 hours \pm 2.3 SE. Laboratory observations were made on 50 unmated females. Addi- tional field observations of the various behaviors were conducted from Aug. 15, 2000, through April 15, 2001. Electron micrographs were made of brochosomes with a Philips scanning electron microscope.

Adult female GWSS can be categorized as young virgins (unresponsive to courtship) mature virgins (responsive to courtship), and mated. The females usually don't mate more than once. Thirty-five pairs were observed in an environmentally controlled room with lemon, grapefruit, oleander and grape plants, beginning at about sunrise. Of the 35 pairs, courtship lasted 6.2 minutes $\pm 0.3 \mathrm{SE}$ and copulation lasted for 165.0 minutes $\pm 5.0 \mathrm{SE}$. Mating is thought to occur mainly between 6 p.m. and dusk in Florida; in these experiments, mating was completed before noon by 33 of the 35 pairs. Females only mated once while males mated up to four times. Females never mated earlier than 96 hours after eclosion, but sometimes didn't mate until 14 days after eclosion.

Following mating, four preovipositional behaviors were observed.

Anointing. Insects secreted spherical brochosomes from the anus and spread them on the abdomen with the hind tibia; this behavior is known in the literature as "anointing" (Rakitov 1996). It occurs with the stylets inserted into the plant stem. The time required for this behavior by the females was 70.0 seconds $\pm 0.9 \mathrm{SE}$. While this behavior is associated with GWSS preoviposition behavior, it occurs at other times by females, males and nymphs and doesn't always have brochosomes associated with the secretions.

Ball-rolling. Females slowly moved their abdomens to a 40-degree angle to the plant stem with stylets inserted. They secreted a grayish drop of liquid, which was removed from the anus with the hind leg. This material was kneaded with the tarsi of all three pairs of legs and the remnant was flicked away. This behavior, referred to here as "ball-rolling," required 80.1 seconds $\pm 0.5 \mathrm{SE}$. This material contained spherical brochosomes. Ballrolling behavior preceded the wingspot formation. 


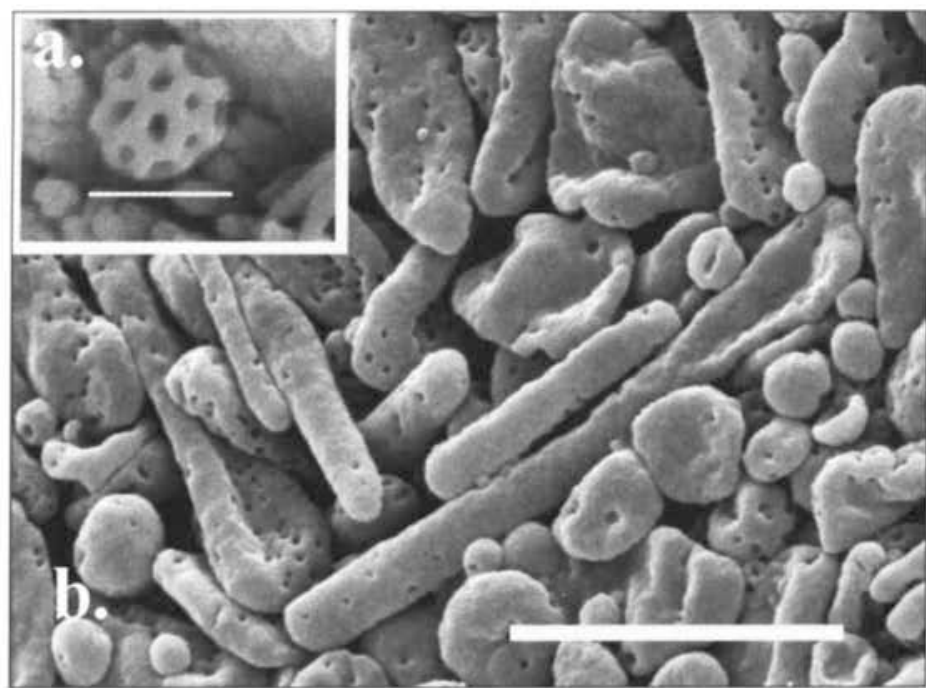

(A) Scanning electron micrograph (SEM) of spherical brochosome from 4th instar GWSS nymph (bar $=0.5$ micrometers); (B) SEM of the forewing spot of female GWSS reveals rodshaped brochosomes which are applied to egg masses (bar $=\mathbf{5 . 0}$ micrometers).

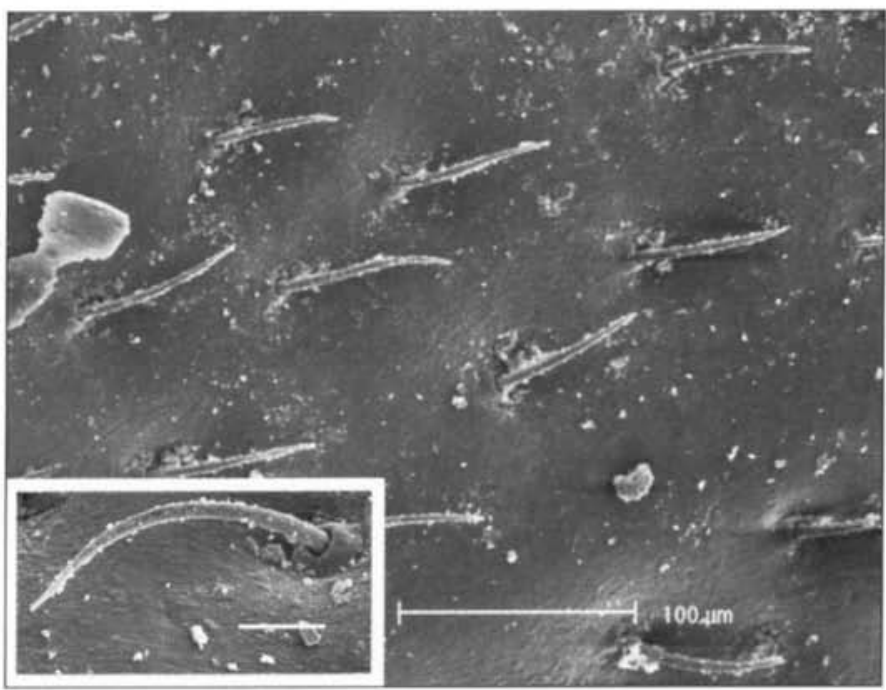

Scanning electron micrograph (bar $=100.0$ micrometers) of hair patch or pallet on forewing of female GWSS used for rodshaped brochosome storage with close-up of a hair (inset, bar = 20.0 micrometers). The mean number of hairs per forewing was $167+/-1.1$ SE $(n=35)$ for females and $2.3+/-0.34$ SE $(n=35)$ for males.
Wing-spot formation. At the onset of wing-spot formation, the females lifted the abdomen to about a 40-degree angle. The tip of the abdomen was moved from side to side and alternately touched with the left and right hind tibia. Both hind tibia were used to move white liquid secreted from the anus, and these alternations continued until an average of five white drops were placed on a hair patch on each forewing. The mean for spot formation was 89.2 seconds $\pm 0.6 \mathrm{SE}$. Prior to drying, the forewings looked as though they had been painted with "Wite-Out." The material dried on the wings, giving a chalky appearance.

Searching and oviposition. The searching behavior for oviposition sites was extremely variable ranging from 3 minutes to 36 hours. Prior to selecting a suitable leaf, $3.0 \pm 0.4 \mathrm{SE}$ leaves were rejected. Females made slits in the epidermis on the underside of the leaf with the ovipositor. To begin oviposition, two eggs were inserted. Then the female scraped rod-shaped brochosomes from the wing spots with the hind tibia onto the area around the egg mass. An additional slit was made and two more eggs were inserted and powdered with brochosomes. This procedure was followed until the egg mass was complete. In the event the mass had an odd number of eggs, the single egg was laid last. The remainder of the brochosomes were scraped from the forewings upon completion of the egg mass. The 35 females laid a mean of 12.5 eggs $\pm 0.8 \mathrm{SE}$ in the first batch with a mean oviposition time of 47.5 minutes $\pm 2.8 \mathrm{SE}$.

None of the 50 unmated females observed in the laboratory secreted brochosomes.

Field observation. Each of these behaviors was observed by the author in field conditions, but not from mating through oviposition. Between $\mathrm{Au}$ gust 2000 and April 2001, anointing was observed 43 times, ball-rolling 23 times, and wing-spot formation 52 times in citrus. Two females generated wing spots on Jan. 9, 2001, in Redlands, Calif., and two generated wing spots in citrus on Jan. 11, 2001, in Temecula. One egg mass was recovered in each of the areas in January.

\section{What are brochosomes for?}

GWSS nymphs and adults produce spherical brochosomes. Only females of leafhopper species studied are known to produce rod-shaped brochosomes, and wing spots contain only rod-shaped brochosomes. The brochosomes produced by the nymphs are more like the ones reported by Rakitov (2000).

There are three key points. First, female GWSS only produce rod- shaped brochosomes after mating, and they typically mate only once. Second, wing spots from brochosome secretions occur just prior to oviposition. Lastly, females generate wing spots prior to the oviposition of each egg mass.

Although females remove nearly all the brochosomes from their wings during oviposition, residue accumulates during the egg-laying life of the female. However, these residues can be obscured by glue on the yellow sticky traps used to attract GWSS. Attempts are being made to relate the numbers of females caught in traps and by other monitoring methods to oviposition in grape or citrus. In the past, no method of biologically linking trap catches to oviposition in a given vegetation existed. This made it difficult to determine if sharpshooters were randomly moving through or if they were in an area to feed and/or lay eggs.

What are brochosomes for? Suggested functions include: (1) prevention of egg desiccation; (2) protection from ultraviolet (UV) light; (3) protection from parasitoids; (4) protection from predators; (5) signals to other females that a certain leaf already has eggs laid in it; and (6) antimicrobial. The significance of brochosome accumulation is unknown but may be useful in interpreting oviposition. 
These observations lay the groundwork for future studies on antimicrobial roles of brochosomes and the effect of brochosomes on predator and parasitoid behavior. Furthermore, it may be advantageous to collect females with white spots to establish and augment GWSS colonies and bioassays because these females are mated and will lay eggs within a few hours to a couple of days.

R. L. Hix is Extension Specialist and Entomologist, Department of Entomology, UC Riverside. Video files compatible with the latest version of the Windows Media player are available from the author for anointing, ball-rolling, and powdering of the egg mass with brochosomes.

\section{References}

Day MF, Briggs M. 1958. The origin and structure of brochosomes. J of Ultrastructure Res 2:239-44.

Mayse MA. 1981. Observations on the occurrence of chalky deposits on forewings of Oncometopia orbona (F.) (Homoptera: Cicadellidae). Proc of Ark Ac of Science 35:84-6.

Nielson MW, May CJ, Tingey WM. 1975 Developmental biology of Oncometopia a/pha. Annals of Entomol Soc of Am 68:401-3.

Rakitov RA. 1996. Post-moulting behaviour associated with Malpighian tubule secretions in leafhoppers and treehoppers (Auchenorrhyncha: Membracoidea). Eur $\mathrm{J}$ of Entom 93:167-84

Rakitov RA. 2000 . Secretion of brochosomes during the ontogenesis of a leafhopper, Oncometopia orbona (F.) (Insecta, Homoptera, Cicadellidae). Tissue and Cell 32:28-39.

Riley CV, Howard LO. 1893. The glassywinged sharpshooter. Insect Life 5:150-4.

Smith DS, Littau VG. 1960. Cellular

specializion in the excretory epithelia of an insect, Macrosteles fascifrons Stal (Homoptera: Cicadellidae). J of Cell Biol 8:103-13.

Sorensen SJ, Gill RJ. 1996. A range extension of Homalodisca coagulata (Say) (Hemiptera: Clypeorrhyncha: Cicadellidae) to southern California. Pan-Pac Entomol 72:160-1.

Swain RB. 1936. Notes on the oviposition and life history of the leafhopper Oncometopta undata Fabr. (Homoptera:

Cicadellidae). Entomological News 47:264-6.

Tulloch GS, Shapiro JE. 1953.

Brochosomes. Bulletin of the Brooklyn Entomological Society 48:57-63.

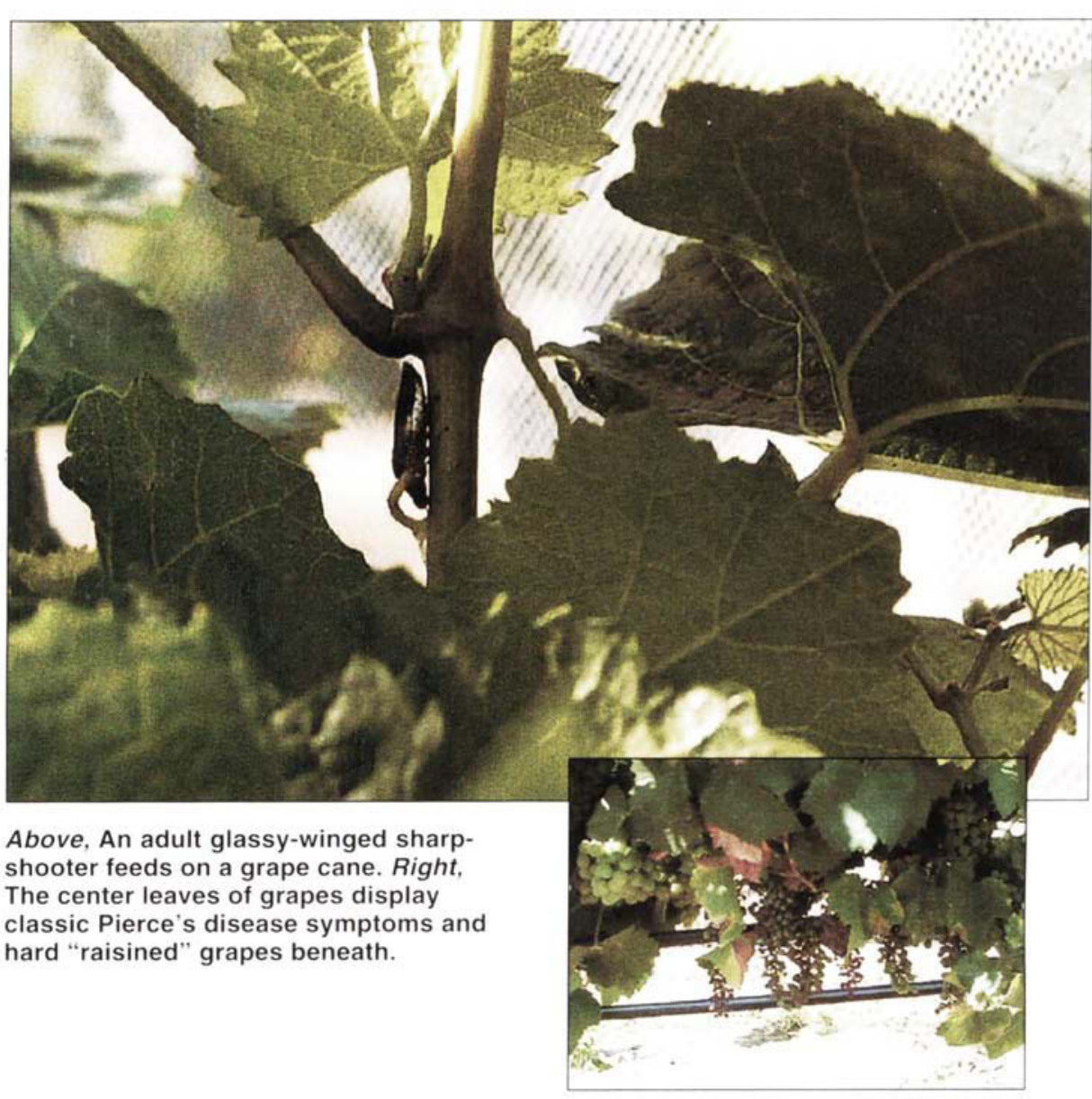

\section{Insecticides sought to control adult glassy- winged sharpshooter}

David H. Akey $\triangleleft$ Thomas J. Henneberry $\sqcup$ Nick C. Toscano

The bacterium that causes

Pierce's disease (Xylella

fastidiosa) is transmitted to grapevines by the glassy-winged sharpshooter (GWSS). Insecticides were evaluated for efficacy and residual activity against adult GWSS on grapevines. Ten insecticides were tested in the cyclo-chlorinated, carbamate, organic phosphate, pyrethroid and neonicotinoid chemical classes.

\begin{abstract}
Results from field trials indicate that the pyrethroids and neonicotinoids are promising control agents. Information on efficacious and environmentally compatible chemical control will be helpful in developing integrated pest management to protect California vine yards from Pierce's disease, as well as insecticide resistance man agement within crop-management production systems.
\end{abstract}

